\title{
Financial competitiveness evaluation on sporting goods listed enterprises: A China study
}

\author{
Feng Ran ${ }^{1 *}$ and Xiaoling Zhang ${ }^{2}$ \\ ${ }^{1}$ Institute of Physical Education, Chongqing University, Chongqing 400045, China. \\ 2 Department of Building and Real Estate, Faculty of construction and Land Use, The Hong Kong Polytechnic University, \\ Hong Kong.
}

Accepted 29 April, 2011

\begin{abstract}
The sporting goods listed enterprises faces more severe financial challenges in the global financial crisis. An effective approach for evaluating the financial competitiveness level is essential for meeting this challenge to improve the sustainable competitiveness of the sporting goods production industry. This approach starts from setting up a coherent conceptual and analytical framework covering different aspects, including profitability capability, debt paying capability, and operation capability. In this paper, an evaluation system for the integrated index competitiveness evaluation system (IICE) is presented and aimed at studying the financial competitiveness of the sporting goods listed enterprises. This is based on 10 indicators drawn from previous literatures in consultation with a group of experts in this field. Principal component analysis (PCA) is applied to assist in identifying the principal components for evaluating the financial competitiveness of the sporting goods enterprises. The findings lead to suggestions for further study into investigating effective business strategies for improving the financial competitiveness for sporting goods listed enterprises in China.
\end{abstract}

Key words: Competitiveness, financial, evaluation system, sporting goods listed enterprises.

\section{INTRODUCTION}

According to the World Federation of Sporting Goods Industries, China has become the largest sporting goods production base, producing some $70 \%$ of the world's sporting goods. In China, sporting goods, including sportswear and equipment, take up $80 \%$ of China's sports industry. Recently, the successful holding of the Beijing Olympic Games and Guangzhou, the Asian games, has enormously boomed the rapid development of the sporting goods industry. Driving by the tremendous business opportunities, internationally renowned brands like Nike and Adidas have expanded investment in China. Meanwhile, the domestic manufacturers such as Li Ning, Anta and $361^{\circ}$, are experiencing stronger growth in Chinese market. It is believed that the enhancement of the competitiveness of a sporting goods company is one of the most important strategic tasks in the sports industry. The challenge to win in the competitive battle

${ }^{*}$ Corresponding author. E-mail: ranfong1973@sina.com. Tel: +86-0 13308250808 . has become essential in modern business, while the dynamically growing competitive environment and the global financial crisis have forced the sporting goods companies to pay more attention to their competitiveness in the financial assets. However, a lot of research has been conducted in the organizational competitiveness; few of them have focused on the study of financial competitiveness on the business enterprises. Therefore, it is of prime importance to find an evaluation approach to study the financial competitiveness of a firm in order to conduct effective competitive strategies in the market.

This paper aims to investigate the financial competitiveness for sporting goods listed enterprises by developing an evaluation model. The evaluation approach is an integration of evaluation indices, applied collectively to reveal a theoretical competitiveness constructs, for example the gross profit, earnings per share, return on equity, etc. By incorporating these financial indicators, an integrated index competitiveness evaluation (IICE) system for sporting goods enterprises is formulated. The IICE system can provide a theoretical basis and effective technical assistance for decision- makers in the sporting 
goods industry in the future.

\section{LITERATURE REVIEW}

Research efforts made to define the concept of competitiveness can be found extensively. Investigations of the topic can be conducted from the perspective at national, industrial, firm or project level (Zhang et al., 2010). The distinction between these four levels is made as the analytic context is significantly different at different level. For example, Scott and Lodge (1985) consider that national competitiveness refers to a country's ability to create, produce, distribute and/or service products in international trade, while earning rising returns on its resources. Buckley et al. (1988) defines industrial competitiveness as both efficiency (reaching goals at the lowest possible cost) and effectiveness (having the right goals). Competitiveness involves a combination of assets and processes, where assets are inherited (for example natural resources) or created (for example infrastructure), and processes transform assets to achieve economic gains from sales to customers (Department of Industry, Science and Resources, 2001).

Ivancevich et al. (1996) define competitiveness as the degree to which a firm can, under free and fair market conditions, produce goods and services that meet the demand of international markets while simultaneously maintaining or expanding the real incomes of its employees and owners. Traditionally, the competitiveness of a product or service refers to its capability to compete in the market, satisfy customers, take up market share, and make profits for shareholders (Zhang et al., 2010).

There are also a lot of studies about the financial competitiveness of business enterprises. Wen (2006) proposed an AHP-fuzzy comprehensive evaluation method, and comprehensively evaluated the currently enterprises' financial competitiveness. Wang and $\mathrm{Li}$ (2007) drew the overall impression of the enterprises' competitiveness through selecting listed firms' financial index of the equipment manufacturing industry. Dai and Wei (2010) developed a financial competitiveness evaluation model based on the method of analytic hierarchy process (AHP), which was built in the four areas of solvency, operational capacity, profitability and development capacity. However, it can be summarized that most of the studies mentioned herein are confined as qualitative research. The result of the qualitative research is rather subjective, and less than trustworthy.

Therefore, very few of them have addressed comprehensive financial indicators set, tailored for evaluating the competitiveness of sporting goods listed enterprises. And there is a lack of quantitative evaluation approach by combining the set of indicators to assess competitiveness of sporting goods enterprises. There is a necessity to find out an appropriate method in this paper, to facilitate the study in filling up the research gap.

\section{INTEGRATED INDEX COMPETITIVENESS EVALUATION SYSTEM (IICE)}

\section{Research method}

There is no one single indicator used to measure the financial competitiveness of the sporting goods listed enterprises. The evaluation about the financial competitiveness is therefore, considered as a multi-level and more complex problem, and the effects about the enterprise financial competitiveness caused by each index are different.

In order to develop the IICE system, the first task is to identify the indicators that can demonstrate the financial capability and to organise the indicators into an appropriate structure based on principles such as ease of operation and cost effectiveness. This then enables the principal component analysis method to be used to extract the principal component factors and calculate the loadings with each of the investigated cases. This is followed by the group analysis of the sustainability level of urban land use among the capital cities and municipalities in China. The advantages have been identified in the application of PCA in land use changes ( $\mathrm{Li}$ and Yeh, 1998) and land use evaluation practice (Yu, 1993).

\section{Indicator selection and data collection}

Obviously, the financial competitiveness of the listed enterprises has been analysed from various scale perspectives (Feng and Wang, 2000; Wu et al., 2010). Indicators are powerful tools to simplify, quantify, and communicate information on processes such as society-nature interaction that are too complex to be measured, and perceived directly (Hammond et al., 1995). A literature review was undertaken to provide the appropriate financial indicators for setting up the IICE system. In line with the literature review, a preliminary indicator list has been proposed by including the relevant indicators mentioned in the previous literatures. For example, Wang and Li (2007) opined that 'quick ratio', 'asset-liability ratio' and 'total asset turnover' can be considered as the key indicators for evaluating the financial competitiveness for listed enterprises. Besides, the research has also added indicators, such as, 'net profit growth rates ', 'three year capital average growth rates' , 'net capital profit ratio', 'total capital profit ratio', 'total asset growth rates' and 'sales income growth rates' into the indicator system. Feng and Wang (2000) proposed another three financial indicators, "gross profit margin", "earnings per share" and "current asset turnover" to conduct the performance evaluation process for airlines with financial ratios taken into consideration.

In order to ensure effective readability and proper expression of their meanings, these indicators were presented to 10 business management practitioners and academics as a pilot study. The respondents were invited to assess whether the indicator framework is appropriate, whether the proposed indicators are appropriate in capturing the competitiveness of those sporting goods listed enterprises, whether the terminology was correct, or whether some indicators could be deleted from the list or others could be added. Valuable comments were received and amendments were made accordingly, which led to the confined list of three pillars of issues and 10 indicators as shown in Table 1. The two indicators "sales income growth rates" and "free cash flow ratio" were deleted from the indicator framework according to the respondents' opinions. In this context, the revised indicator list can be classified into three major groups: profitability capability, debt paying capability and operation capability. By communicating with experts in the business management area, the evaluation framework can be tailored with the specific circumstances of local areas.

The cases used for this study are those sporting goods listed enterprises in China, including Lining, Anta, XTEP, China Dongxiang and Peak (Appendix). The relevant data for the 10 
Table 1. The Financial competitiveness indicator system.

\begin{tabular}{|c|c|c|c|}
\hline Category & Indicator & Unit & References \\
\hline \multirow{5}{*}{$\begin{array}{l}\text { Profitability } \\
\text { capability }\end{array}$} & $\mathrm{X}_{1}$-Gross profit & RMB:1000 & Wang and Li, 2007; Wu et al., 2010 \\
\hline & $\mathrm{X}_{2}$-Gross profit margin & $\%$ & Feng and Wang, 2000; Jin, 2003; Wu et al., 2010 \\
\hline & $\mathrm{X}_{3}$-Earnings per share & Cents & Feng and Wang, 2000; Jin, 2003; Wu et al., 2010 \\
\hline & $\mathrm{X}_{4}$-Shareholders' equity per share & Cents & Wang and Li, 2007; Wu et al., 2010 \\
\hline & $\begin{array}{l}\mathrm{X}_{5} \text {-Return on average total } \\
\text { shareholders' equity }\end{array}$ & $\%$ & Wang and Li, 2007; Wu et al., 2010 \\
\hline \multirow{3}{*}{$\begin{array}{l}\text { Debt paying } \\
\text { capability }\end{array}$} & $\mathrm{X}_{6}$ - Current ratio & $\%$ & Wang and Li, 2007; Wu et al., 2010 \\
\hline & $\mathrm{X}_{7}$-Quick ratio & $\%$ & Wang and Li, 2007; Wu et al., 2010 \\
\hline & $\mathrm{X}_{8}$-Asset-liability ratio & $\%$ & Wang and Li, 2007; Jin, 2003 \\
\hline \multirow{2}{*}{$\begin{array}{l}\text { Operation } \\
\text { capability }\end{array}$} & $\mathrm{X}_{9}$-Current asset turnover & $\%$ & Feng and Wang, 2000; Wu et al., 2010 \\
\hline & $\mathrm{X}_{10}$-Total asset turnover & $\%$ & Wang and Li, 2007; Wu et al., 2010 \\
\hline
\end{tabular}

Table 2. Eigenvalues and variability contributions of IICE (\%).

\begin{tabular}{lccc}
\hline Factor & Factor1 & Factor2 & Factor3 \\
\hline Eigenvalue & 4.518 & 3.061 & 1.196 \\
Percentage variability contributions & 45.18 & 30.62 & 11.95 \\
Cumulative variability contribution rate & 45.18 & 75.80 & 87.75 \\
\hline
\end{tabular}

indicators were acquired from the annual report of Lining (2007, 2008, 2009), the annual report of Anta (2007, 2008, 2009), the annual report of XTEP $(2007,2008,2009)$, the annual report of China Dongxiang $(2007,2008,2009)$ and the annual report of Peak (2007, 2008, 2009).

\section{PRINCIPAL COMPONENT ANALYSIS AND RESULT OF IICE}

Principal component analysis (PCA) is a popular means for making comparisons between objects' measures on several dimensions or criteria, such as the welfare level between individuals (Maasoumi and Nickelsburg 1988). To do this, it linearly transforms a set of original variables into a new set of variables that are uncorrelated (orthogonal) with each other (Ku et al., 1995). The method relies solely on the variation and co variation of the data matrix to construct weights in the indexes, which are then used to produce a small number of comprehensive variables, in place of many original variables, simplify the data structure and minimise original data information loss. Many procedures have been proposed for determining the number of components to be retained in the PCA model (Jackson, 1991) and additionally, although somewhat controversially (Sternberg, 1977), the method can be used to help identify the concepts underlying the data. It is also well supported by standard statistical software and therefore, in the current context, it provides a simple and efficient method to identify the groups or concepts for use in evaluating the financial competitiveness of the sporting goods listed enterprises.

The eigenvalues and eigenvectors of the PCA correlation matrix based and the first three eigenvalues are given in Table 2. As can be seen, the contribution rate is calculated from the Varimax normalized factor analysis. This suggests that PCA can be used in several different ways in constructing the competitiveness level of the sporting goods listed enterprises. In accordance with the minimum " $m$ " selection criteria $\left(E_{i}>85 \%\right)$, the three eigenvalues of the cumulative variability contributions rate $\mathrm{E}_{3}$ is $87.75 \%$.

The values of the eigenvectors of the three components are given in Table 3 , the vectors being scaled so that the maximum weighting is 0.927 .

$$
\begin{aligned}
& F_{1}=0.927^{*} X_{6}+0.926^{*} X_{7}+0.539 * X_{4}+0.502^{*} X_{2}+0.437 * X_{1}+0.256^{*} X_{3}-0.702 * X_{9} \\
& -0.780^{*} X_{8}-0.785^{*} X_{10}
\end{aligned}
$$


Table 3. Factor loadings for first three principal components.

\begin{tabular}{cccc}
\hline Variable & F1 & F2 & F3 \\
\hline$X_{6}$ & 0.927 & -0.183 & 0.185 \\
$X_{7}$ & 0.926 & -0.186 & 0.188 \\
$X_{4}$ & 0.539 & 0.702 & -0.094 \\
$X_{2}$ & 0.502 & 0.491 & 0.659 \\
$X_{1}$ & 0.437 & 0.858 & -0.046 \\
$X_{3}$ & 0.256 & 0.926 & -0.145 \\
$X_{9}$ & -0.702 & 0.652 & 0.049 \\
$X_{8}$ & -0.780 & 0.110 & 0.250 \\
$X_{10}$ & -0.785 & 0.476 & -0.088 \\
Name & Solvency capability & Sustainable profit making & Capital management \\
& factor & capability factor & capability factor \\
\hline
\end{tabular}

$$
\begin{aligned}
& F_{2}=-0.183 * X_{6}-0.186 * X_{7}+0.702 * X_{4}+0.491 * X_{2}+0.858 * X_{1}+0.926 * X_{3}-0.652 * X_{9} \\
& +0.110 * X_{8}+0.476 * X_{10} \\
& F_{3}=0.185 * X_{6}+0.188 * X_{7}-0.094 * X_{4}+0.659 * X_{2}-0.046 * X_{1}-0.145 * X_{3}+0.049 * X_{9} \\
& +0.250 * X_{8}-0.088 * X_{10}
\end{aligned}
$$

\section{Factor 1: Solvency capability factor}

As Formula 1 to 3 , and Table 3 show, the first component $F_{1}$, is predominantly loaded with $X_{6}(0.927)$ and $X_{7}$ (0.926). The first principal component (Factor 1) stores the maximum contents of the variance of the original data set ( $\mathrm{Li}$ and Yeh, 1998), which include the components: $\mathrm{X}_{6}$ - current ratio and $\mathrm{X}_{7}$ - quick ratio

The financial competitiveness of the sporting goods listed enterprises can be driven by several elements, including debt management and asset management aspects. For example, $X_{6}$ and $X_{7}$ has a high loading on Factor 1 , indicating that debt management capability can greatly affect the competitiveness level of the sporting goods listed enterprises. This is becoming even more critical in the context of the global financial crisis. Those who gained the capability to solve the debt capability can become the leader in the competitive market in China. This finding is echoed with Wu et al. (2010), who opined that the solvency capability played a noticeable role of spurring the growth of sporting goods listed enterprises in China.

\section{Factor 2: Sustainable profit making capability factor}

The second principal component (Factor 2) describes the largest amount of the variance in the data that is not already described by the first principal component, and so forth (Taylor, 1977). Factor 2 gives high positive weightings to $X_{3}$ (0.926), $X_{1}(0.858)$ and $X_{4}(0.702)$ where; $\mathrm{X}_{3^{-}}$earnings per share; $\mathrm{X}_{1^{-}}$gross profit; $\mathrm{X}_{4^{-}}$ shareholders' equity per share.

This indicates that a sustainable profit making capability should have a healthy shareholder structure and the way to make profit in the market. By operating shareholder's equity, the sporting goods listed enterprises can gain sufficient capital for producing sporting goods, and the outcomes from the store market can help encourage the sustainable business operation. This demonstrates that it is significant for business decision makers to allocate and manage shareholders' resources in a sustainable way.

\section{Factor 3: Capital management capability factor}

The third principal factor (Factor 3 ) has principal loadings with $X_{2}(0.659)$ and $X_{8}(0.250)$, which carry much information in the proportion of capital management capability aspects, where; $\mathrm{X}_{2}$ - gross profit margin; $\mathrm{X}_{8}$ - asset-liability ratio.

The result points to the links between the capital management capabilities with the competitiveness of the sporting goods listed enterprises. Capital has become one of the most significant resources for those manufacturing enterprises nowadays. In order to accumulate sufficient capital, one of the efficient ways is to manage the asset from producing and selling the sporting goods, efficiently and sustainably. On the other hand, the gross profit margin can indicate how, and to what extent, the 
capital can be controlled and well managed. In this context, the capital can always be ready for producing enough sporting goods in the market.

\section{Conclusions}

The evaluation of the financial competitiveness of the sporting goods listed enterprises in China is currently a rather rudimentary, subjective issue, while the complexities involved warrant a more sophisticated and objective approach. The integrated index competitiveness evaluation system (IICE) in this study has involved profitability capability, debt paying capability and operation capability aspects. Using the methods of principal component analysis, three principal components were extracted and named according to their intuitive meaning, 'solvency capability factor', 'sustainable profit making capability factor' and 'capital management capability factor'. IICE offers a theoretical basis for proposing appropriate business strategies in order to promote and enhance the overall competitiveness of the sporting goods listed enterprises.

The proposed IICE system can not only help business managers identify the status quo of the competitiveness level in the financial aspect, but also help the industry authorities to make relevant policy changes as well as actions based on the assessment results. In this context, a further research based on the findings of this paper has to be designed to provide appropriate tools, instruments and methodologies, to improve the competitiveness of sporting goods enterprises. The findings in this study can also provide relevant experiences sharing for other industries and sporting goods industry in other countries, which can be of interest to the international audience of business managers or decision makers.

\section{REFERENCES}

Buckley PJ, Pass CL, Prescott, K (1988). Measures of International Competitiveness: A critical Survey. J. Mark. Manage., 4(2): 175-200.
Dai LX, Wei SX (2010). Financial Competitiveness Evaluation of Chinese Listed Companies of Electrical Equipment Section: Based on AHP. International Conference on Logistics Engineering and Intelligent Transportation Systems (LEITS), 26-28 Nov. 2010.

Department of Industry, Science and Resources (2001). Destination Competitiveness: Development of a Model with application to Australia and the Republic of Korea. An Australian Govt. Report, October.

Feng CM, Wang RT (2000). Performance evaluation for airlines including the consideration of financial ratios. J. Air Transp. Manage., 6(3): 133-142.

Hammond A, Adriaanse A, Rodenburg E, Bryant D, Woodward R (1995). Environmental Indicators, a Systematic Approach to Measuring and Reporting on Environmental Policy Performance in the Context of Sustainable Development. World Resources Institute, Washington, DC.

Ivancevich JM, Lorenzi P, Skinner SJ, Crosby PB (1996). Management Quality and Competitiveness. Irwin, London.

Jackson JE (1995). A user's guide to Principal Components, Wiley, New York.

Sternberg RJ (1977). Intelligence, information processing, and analogical reasoning: The componential analysis of human abilities. Hillsdale, NJ: Erlbaum.

Jin B (2003). Theory and Methodology of Measuring Enterprise Competitiveness. (In Chinese). China Ind. Econ., 3: 5-13.

Ku W, Storer RH, Georgakis C (1995). Disturbance detection and isolation by dynamic principal component analysis. Chemometr. Intell. Lab. 30(1): 179-196.

Li X, Yeh, AGO (1998). Principal component analysis of stacked multitemporal images for the monitoring of rapid urban expansion in the Pearl River Delta. Int. J. Rem. Sens., 19(8): 1501-1518.

Maasoumi E, Nickelsburg G (1988). Multivariate measures of well being and an analysis of inequality. J. Bus. Econ. Stat., 6: 327-334.

Scott BR, Lodge, GC (1985). US Competitiveness in the World Economy. Harvard Business School Press, Boston.

Wang M, Li Q (2007). Empirical Analysis on Company's Competitiveness from Financial Index. China Bus. Rev., 6(2): 54-59.

Wen LX (2006). The Empirical Analysis on Enterprise Financial Competitiveness Evaluation. International Conference on E-Product E-Service and E-Entertainment (ICEEE), pp. 1-4.

Wu YN, Chen Z, Li JJ (2010). Evaluation of Brand Competitive Ability in Chinese Sporting Productions Listed Companies. China Sport Sci., 30(1): 30-35

Yu, JL (1993). Multiple statistics on agricultural experiments. Beijing Agricultural University Press, Beijing.

Zhang XL, Shen LY, Wu YZ, Peng Y (2010). Core competitiveness indicators: a study of real estate developers in China. Facilities, 28(11/12): 526-541. 


\section{APPENDIX}

Data for evaluation on the competitiveness of the Sporting goods listed enterprises

\begin{tabular}{|c|c|c|c|c|c|c|c|c|c|c|}
\hline Manufacturer & $\mathrm{X}_{1}$ & $\mathrm{X}_{2}$ & $\mathrm{X}_{3}$ & $\mathrm{X}_{4}$ & $X_{5}$ & $\mathrm{X}_{6}$ & $\mathbf{X}_{7}$ & $\mathrm{X}_{8}$ & $X_{9}$ & $\mathrm{X}_{10}$ \\
\hline Anta (2009) & $2,472,894.00$ & 42.1 & 50.23 & 203.84 & 26.2 & 5.63 & 5.20 & 0.158 & 1.20 & 0.963 \\
\hline Anta (2008) & $1,848,573$ & 40 & 35.94 & 179.95 & 20.7 & 9.42 & 8.70 & 0.093 & 1.06 & 0.936 \\
\hline Anta (2007) & 999,907 & 33.5 & 25.26 & 166.69 & 24.5 & 8.62 & 7.71 & 0.104 & 0.72 & 0.645 \\
\hline Anta (2006) & 313,228 & 25.1 & 8.19 & 13.22 & 84.5 & 0.96 & 0.71 & 0.134 & 2.11 & 1.460 \\
\hline XTEP (2009) & $1,387,800.00$ & 39.1 & 29.79 & 1.37 & 23 & 5.80 & 4.93 & 0.180 & 1.05 & 0.974 \\
\hline XTEP (2008) & $1,064,300.00$ & 24.3 & 26.84 & 1.21 & 34.8 & 4.80 & 4.38 & 0.195 & 0.93 & 0.875 \\
\hline XTEP (2007) & 443100 & 31.12 & 15.11 & 2.8 & 94.9 & 1.90 & 1.43 & 0.690 & 1.76 & 1.511 \\
\hline XTEP (2006) & 136100 & 11.95 & 3.41 & 2 & 31.3 & 1.20 & 0.79 & 0.641 & 1.17 & 0.926 \\
\hline $361^{\circ}(2009)$ & $1,193,803$ & 39.4 & 42.1 & 186.5 & 44.7 & 2.40 & 2.10 & 0.256 & 1.13 & 0.949 \\
\hline $361^{\circ}(2008)$ & 348,028 & 26.4 & 11.9 & 142.3 & 80.5 & 1.25 & 1.03 & 0.385 & 0.92 & 0.845 \\
\hline $361^{\circ}(2007)$ & 76,923 & 20.6 & 1.5 & 38.3 & 23 & 1.33 & 1.07 & 0.724 & 1.27 & 1.143 \\
\hline $361^{\circ}(2006)$ & 27,058 & 10.3 & 0.7 & 15.4 & 19.2 & 1.26 & 1.08 & 0.067 & 1.07 & 0.955 \\
\hline China Dongxiang (2009) & $2,399,371$ & 45.2 & 25.76 & 129.8 & 20.75 & 12.81 & 12.76 & 0.070 & 0.56 & 0.502 \\
\hline China Dongxiang (2008) & $1,943,762$ & 58.5 & 24.12 & 128.6 & 21.67 & 11.84 & 11.07 & 0.079 & 0.49 & 0.456 \\
\hline China Dongxiang (2007) & $1,000,573$ & 58.5 & 15.89 & 134.78 & 21.67 & 18.45 & 18.17 & 0.090 & 0.29 & 0.275 \\
\hline China Dongxiang (2006) & 535,561 & 62.4 & 7.1 & 19.7 & 174.43 & 2.13 & 1.76 & 0.639 & 1.70 & 1.010 \\
\hline Lining (2009) & $3,969,864$ & 47.3 & 90.75 & 255.3 & 41.3 & 1.70 & 1.36 & 0.468 & 2.65 & 1.560 \\
\hline Lining (2008) & $3,220,374$ & 48.1 & 69.63 & 182.9 & 39.6 & 1.35 & 1.04 & 0.518 & 2.37 & 1.543 \\
\hline Lining (2007) & $2,082,846$ & 47.9 & 45.83 & 168.5 & 30.1 & 2.22 & 1.70 & 0.373 & 2.00 & 1.564 \\
\hline Lining (2006) & $1,508,552$ & 47.4 & 28.65 & 135.7 & 23 & 2.74 & 2.23 & 0.354 & 1.68 & 1.469 \\
\hline Peak (2009) & $1,159,700.00$ & 37.5 & 36 & 143 & 20.9 & 8.40 & 7.80 & 0.130 & 1.01 & 0.910 \\
\hline Peak (2008) & 667800 & 32.7 & 25 & 52 & 48.6 & 2.30 & 1.90 & 0.461 & 1.75 & 1.423 \\
\hline Peak (2007) & 306000 & 30.2 & 11 & 27 & 41.7 & 1.90 & 1.50 & 0.529 & 1.31 & 1.158 \\
\hline Peak (2006) & 177200 & 28.4 & 6 & 0 & 62.2 & 1.60 & 1.10 & 0.622 & 2.06 & 1.915 \\
\hline
\end{tabular}

